\title{
Correction to: Performance analysis of pre-cancerous mammographic image enhancement feature using non-subsampled shearlet transform
}

\author{
T. V. Padmavathy ${ }^{1} \cdot$ M. N. Vimalkumar ${ }^{2} \cdot$ Sivakumar Nagarajan $^{3}$ • \\ Gokul Chandra $\mathrm{Babu}^{3}$. P. Parthasarathy ${ }^{3}$ \\ Published online: 14 July 2021 \\ (C) Springer Science+Business Media, LLC, part of Springer Nature 2021
}

\section{Correction to: Multimed Tools Appl (2018) https://doi.org/10.1007/s11042-018-5951-3}

The reference list in the original publication of this article contains errors. The correct references are given below.

[1] Wani IUI, Hanumantharaju MC, Gopalakrishna MT (2014) Review of mammogram enhancement techniques for detecting breast cancer. IJCA Proceedings on International Conference on Information and Communication Technologies (ICICT) 1:18-22

[2] Kaur T (2014) Image denoising algorithms and DWT: A review. International Journal of Computer Science and Information Technologies 5(5):6135-6137

[3] Mohideen K, Perumal A, Sathik M (2011) Image de-noising and enhancement using multiwavelet with hard threshold in digital mammographic images. International Arab Journal of eTechnology 49-55

The online version of the original article can be found at https://doi.org/10.1007/s11042-018-5951-3

T. V. Padmavathy tvpsweeti@gmail.com

1 Department of Electronics and Communication Engineering, R.M.K. Engineering College, Chennai, India

2 Department of Electronics and Communication Engineering, R.M.D. Engineering College, Chennai, India

3 Vellore Institute of Technology, Vellore, India 
[4] Kanamadi M, Waghamode V, Bandekar S (2013) Alpha weighted quadratic filter based enhancement for mammogram. Proceedings of International Conference on Emerging Research in Computing, Information, Communication and Applications (ERCICA) 68-74

[5] Zhang X, Xie H (2009) Mammograms enhancement and denoising using generalized Gaussian mixture model in nonsubsampled contourlet transform domain. Journal of Multimedia 4(6):389-396

[6] Kidsumran V, Chiracharit W, Higuchi K (2013) Contrast enhancement using wavelet transform and adaptive denoising in mammograms. International Workshop on Advanced Image Technology 94-98

[7] Zhang X (2015) Image denoising using shearlet transform and nonlinear diffusion. The 5th International Conference on Computer Engineering and Networks (CENet). 259, 033

[8] Savitha V, Kadhambari T, Sheeba R (2014) Multimodality medical image fusion using NSCT. International Journal of Research in Engineering \& Advanced Technology (IJREAT) 1(6)

[10] Patel VK, Uvaid S, Suthar AC (2012) Mammogram of breast cancer detection based using image enhancement algorithm. International Journal of Emerging Technology and Advanced Engineering 2(2012):143-147

[11] Ramamoorthy M, Anees Barvin K (2014) Medical image fusion using Gabor and gradient measurement. International Journal of Innovative Research in Science, Engineering and Technology 3(3):2077-2083

[12] Kumar NH, Amutha S, Babu DR (2012) Enhancement of mammographic images using morphology and wavelet transform. Computer Technology Application 3(1):192-198

[13] Roy S, Sinha N, Sen AK (2010) A new hybrid image denoising method. International Journal of Information Technology and Knowledge Management 2(2):491-497

[14] Cao Y, Li S, Hu J (2011) Multi-focus image fusion by nonsubsampled shearlet transform. 2011 Sixth International Conference on Image and Graphics 17-21

[15]Ren X, Wei Z, He Z, Sun X, Geng P (2015) Denoising method based on the nonsubsampled shearlet transform. 2015 International Industrial Informatics and Computer Engineering Conference 237-240

[16] Gowri Shankar C, Balakumaran T, Shanmugam A (2011) A multi-resolution approach to denoising and enhancement of pre-cancerous features in mammograms. International Journal of Biomedical Engineering and Technology 7(3):242-256

[17] Garud YG, Shahare NG (2013) Detection of microcalcifications in digital mammogram using wavelet analysis. American Journal of Engineering Research 2(11):80-85 
[18] AbuBaker AA (2015) Automatic microcalcification detection using wavelet transform. International Journal of Computer Theory and Engineering 7(1):40-45

[19] Gupta D, Anand RS, Tyagi B (2013) Edge preserved enhancement of medical images using adaptive fusion-based denoising by shearlet transform and total variation algorithm. Journal of Electronic Imaging 22(4):043016

Reference [9] is removed.

In addition, the first part of section 2.2 NSST algorithm should read as follows:

In present years mathematical thresholding model is used to detect the noise in the digital images. The proposed algorithm makes use of an NSST based threshold modelling approach to denoise mammogram images. This process is made with the help of NSST dependent circular shift algorithm [19].

Publisher's note Springer Nature remains neutral with regard to jurisdictional claims in published maps and institutional affiliations. 